\title{
Next-Generation QTL Mapping: Crowdsourcing SNPs, Without Pedigrees
}

\section{Citation}

Edwards, Scott V. 2013. Next-Generation QTL Mapping: Crowdsourcing SNPs, Without Pedigrees. Molecular Ecology 22, no. 15: 3885-3887.

\section{Published Version}

doi:10.1111/mec.12401

\section{Permanent link}

http://nrs.harvard.edu/urn-3:HUL.InstRepos:12336394

\section{Terms of Use}

This article was downloaded from Harvard University's DASH repository, and is made available under the terms and conditions applicable to Open Access Policy Articles, as set forth at http:// nrs.harvard.edu/urn-3:HUL.InstRepos:dash.current.terms-of-use\#OAP

\section{Share Your Story}

The Harvard community has made this article openly available.

Please share how this access benefits you. Submit a story.

Accessibility 
Next-generation QTL mapping: crowdsourcing SNPs, without pedigrees

Scott V. Edwards

Department of Organismic and Evolutionary Biology, Harvard University, Cambridge, MA 02138 USA

For many molecular ecologists, the mantra and mission of the field of ecological genomics could be encapsulated by the phrase "to find the genes that matter" (Mitchell-Olds 2001; Rockman 2012). This phrase of course refers to the early hope and current increasing success in the search for genes whose variation underlies phenotypic variation and fitness in natural populations. In the years since the modern incarnation of the field of ecological genomics, many would agree that the low-hanging fruit has, at least in principle, been plucked: we now have several elegant examples of genes whose variation influences key adaptive traits in natural populations, and these examples have revealed important insights into the architecture of adaptive variation (Hoekstra et al. 2006; Shapiro et al. 2009; Chan et al. 2010). But how well will these early examples, often involving single genes of large effect on discrete or near-discrete phenotypes, represent the dynamics of adaptive change for the totality of phenotypes in nature? Will traits exhibiting continuous rather than discrete variation in natural populations have as simple a genetic basis as these early examples suggest (Prasad et al. 2012, Rockman 2012)? Two papers in this issue (Robinson et al. 2013; Santure et al. 2013) not only suggest answers to these questions but also provide useful extensions of statistical approaches for ecological geneticists to study the genetics of continuous variation in nature. Together these papers, by the same research groups studying evolution in a natural population of Great Tits (Parus major), provide a glimpse of what we should expect as the field begins to dissect the genetic basis of what is arguably the most common type of variation in nature, and how genome-wide surveys of variation can be applied to natural populations without pedigrees.

Keywords: QTL mapping, quantitative traits, pedigree, natural population, life history traits

Great Tits are an ecological 'model organism' and have been the subject of long-term field studies for over 50 years, including the population at Wytham Woods near Oxford, UK. They have provided critical data addressing many important paradigms in life history evolution (Boyce and Perrins 1987), and more recently, how organisms will adapt to climate change (Charmantier et al. 2008). So it was only a matter of time before ecologists began ushering this 18-g songbird into the genomic era, first by building genomic resources such as a transcriptome (Santure et al. 2011), genome sequencing (van Bers et al. 2010), a 'SNP-chip' (van Bers et al. 2012), and a genetic map, allowing the researchers to study genomic variation at thousands of places across the genome; in the case of Robinson et al. (2013) and Santure et al (2013), around 2,500 individuals were surveyed for nearly 
10,000 SNPs. The authors could not have picked traits more daunting for the discovery of single-gene effects: the two papers studied life history traits (clutch size [number of eggs] and total egg mass) in 1000 females as well as a morphological trait (wing length) in $\sim 2000$ individuals, presumably not expecting strong single gene associations with the phenotypic variation, given recent similar studies of quantitative traits such as height in humans (Yang et al. 2010; Yang et al. 2011). Although the heritabilities of the traits they studied are moderate $(0.26-0.51)$, and early QTL results for birds suggest that a one or a few genomic regions might explain a substantial fraction $(\sim 35 \%)$ of variation in traits such as wing length and bill color in pedigreed populations (Tarka et al. 2010; Schielzeth et al. 2011), Slate (2013), using simulations, suggests that we have reason to question these largeeffect QTLs, and that most previous QTL studies in pedigreed populations have overestimated QTL effect sizes. What is certain is that these traits have been of intense interest by ecologists over the years, partly because of their ease of measurement, but also because they are known to vary widely among individuals and across time, as well as in response to environmental change. It is traits such as these that arguably comprise the bulk of phenotypic variation in nature and provide abundant and logical links to changing environments. Additionally, clutch size and egg mass come with a rich theoretical framework predicting trade-offs and negative genetic correlations that might be observable at the level of DNA.

Both papers came to the conclusion that none of the traits studied revealed evidence for strong single gene or single region effects on variation in the traits. One might call this conclusion 'striking', 'unsettling', 'disappointing' or possibly 'liberating', depending on one's perspective. Although many QTL studies in humans and livestock have begun to suggest a role for many genes of small effect in trait variation, for molecular ecologists, this conclusion might be tantamount to a negative result, or at the very least a disappointing result that rules out submission to a weekly journal. But the strength of the papers is that they draw attention to and extend what is essentially a new null model in ecological genomic studies in natural populations, namely a 'polygenic additive' model in which the combined affects of SNPs on each chromosome scale with chromosome size and overall gene content. Although for all three traits there is one chromosome that explains slightly more trait variation than expected given chromosome size, the overwhelming pattern was one of polygenicity of traits in which the amount of trait variance explained scales with chromosome size. In finding this, these papers echo recent conclusions from human genetics, that the 'missing heritability' found in many genomic studies of disease and quantitative traits might be the result of having only applied models focusing on individuals SNPs, rather than on the combined effects of all SNPs simultaneously. Such a conclusion likely portends what we expect to find as ecological genomics marches boldly into traits with continuous variation. Additionally, the new polygenic additive model - a sort of neutral model of ecological genomics - may provide an important benchmark for the field and will at least provide researchers with a hypothesis to test when no loci of strong effect emerge (or even when they do).

The papers are also significant due to the methodological advances they present. Robinson et al. (2013) describes the estimation of a pairwise relatedness 
matrix among sampled individuals using the power of thousands of SNPs. The paper then introduces a series of models which use this matrix not only to estimate the total heritability of a trait, but also to partition this heritability on a perchromosome or even per-region basis, after mapping SNPs to a reference genome in silico (in this case the zebra finch genome). Robinson et al. (2013) then conducted extensive simulations to show that all the various ways of estimating the relatedness matrix, with or without pedigree information, yield valid estimates of heritability and genetic variance components. Perhaps most importantly, these models allow mapping QTLs for quantitative traits in populations without a pedigree. This should come as a boon to the many evolutionary biologists who study species that do not breed easily in controlled environments.

Santure et al. (2013) compared three approaches to detecting QTL chromosome partitioning based on a relatedness matrix, pedigree-based QTL mapping, and genome-wide association - and found that no approach yielded any strong QTL, consistent with a polygenic basis for clutch size and egg mass. Moreover, nominally significant QTL for the two traits did not overlap in the genome, suggesting that the weakly negative genetic covariance found for these traits by previous workers may be transient and that the two traits might vary independently based on condition or environmental factors. Somewhat soberingly, Santure et al. (2013) also show that the power of the pedigree-based QTL mapping study to detect loci of even moderate effect was low, even though it employed $\sim 1700$ markers and $\sim 650$ birds.

Is the 'polygenic additive' model, in which chromosome size predicts variance explained in quantitative traits, the new normal in ecological genomics studies? Are current QTL studies even large enough to reject this model? In one sense, these papers offer an additional salvo and a useful alternative hypothesis in the ongoing debate about power in QTL studies in pedigrees, which recent work suggests may overestimate the strength of QTL effects (Slate 2013). Additionally, these papers forge boldly into dissecting traits that few researchers on animal populations have had the courage, sample sizes or genomic resources to address. It may be that increasing sample sizes yet further and using denser SNP-chips or whole-genome sequencing (Ober and Ayroles 2012) may eventually yield QTLs that even these substantial studies could not detect, particularly in natural bird populations which tend to have low LD between markers (Balakrishnan et al. 2010). Regardless, it is likely that the chromosome partitioning method, and the liberation from pedigrees that it provides, will yield a flood of additional insight into the genomic architecture of many traits of ecological importance, in a range of species that will level the playing field for model and non-model species considerably.

\section{References}

Balakrishnan, C. N., S. V. Edwards, and D. F. Clayton. 2010. The Zebra Finch genome and avian genomics in the wild. Emu 110:233-241.

van Bers NEM, van Oers K, Kerstens HHD, Dibbits BW, Croijmans RPMA, Visser, ME, Groenen MAM. (2010) Genome-wide SNP detection in the great tit Parus 
major using high throughput sequencing. Molecular Ecology, 19 (Suppl 1), 89-99.

van Bers, N. E. M., A. W. Santure, K. Van Oers, I. De Cauwer, B. W. Dibbits, C. Mateman, R. P. M. A. Crooijmans et al. 2012. The design and cross-population application of a genome-wide SNP chip for the great tit Parus major. Molecular Ecology Resources 12:753-770.

Boyce, M. S., and C. M. Perrins. 1987. Optimizing Great Tit Clutch Size in a Fluctuating Environment. Ecology 68:142-153.

Chan, Y. F., M. E. Marks, F. C. Jones, G. Villarreal, M. D. Shapiro, S. D. Brady, A. M. Southwick et al. 2010. Adaptive Evolution of Pelvic Reduction in Sticklebacks by Recurrent Deletion of a Pitx1 Enhancer. Science 327:302-305.

Charmantier, A., R. H. McCleery, L. R. Cole, C. Perrins, L. E. B. Kruuk, and B. C. Sheldon. 2008. Adaptive phenotypic plasticity in response to climate change in a wild bird population. Science 320:800-803.

Hoekstra, H. E., R. J. Hirschmann, R. A. Bundey, P. A. Insel, and J. P. Crossland. 2006. A single amino acid mutation contributes to adaptive beach mouse color pattern. Science 313:101-104.

Mitchell-Olds, T. 2001. Arabidopsis thaliana and its wild relatives: a model system for ecology and evolution. Trends in Ecology \& Evolution 16: 693-700.

Ober, U., J. F. Ayroles, et al. (2012). Using whole-genome sequence data to predict quantitative trait phenotypes in Drosophila melanogaster. PLoS Genet 8(5): e1002685

Prasad, K. V. S. K., B. H. Song, C. Olson-Manning, J. T. Anderson, C. R. Lee, M. E. Schranz, A. J. Windsor et al. 2012. A Gain-of-Function Polymorphism Controlling Complex Traits and Fitness in Nature. Science 337:1081-1084.

Robinson, M. R., A. W. Santure, I. De Cauwer, B. C. Sheldon, and J. Slate. 2013. Partitioning of genetic variation across the genome using multi-marker methods in a wild bird population. Molecular Ecology in press.

Rockman MV (2012) The QTN program and the alleles that matter for evolution: all that's gold does not glitter. Evolution, 66, 1-17.

Santure, A., J. Gratten, J. Mossman, B. Sheldon, and J. Slate. 2011. Characterisation of the transcriptome of a wild great tit Parus major population by next generation sequencing. Bmc Genomics 12:283.

Santure, A. W., I. De Cauwer, M. R. Robinson, J. Poissant, B. C. Sheldon, and J. Slate. 2013. Genomic dissection of variation in clutch size and egg mass in a wild great tit (Parus major) population. Molecular Ecology in press.

Schielzeth, H., B. Kempenaers, H. Ellegren, and W. Forstmeier. 2011. QTL Linkage mapping of zebra finch beak color shows an oligogenic control of a sexually selected trait. Evolution 66:18-30.

Shapiro, M. D., B. R. Summers, S. Balabhadra, J. T. Aldenhoven, A. L. Miller, C. B. Cunningham, M. A. Bell et al. 2009. The Genetic Architecture of Skeletal Convergence and Sex Determination in Ninespine Sticklebacks. Current Biology 19:1140-1145.

Slate, J. 2013. From Beavis To Beak Color: a Simulation Study To Examine How Much QTL Mapping Can Reveal About the Genetic Architecture of Quantitative Traits. Evolution 67: 1251-1262. 
Tarka, M., M. Akesson, D. Beraldi, J. Hernández-Sánchez, D. Hasselquist, S. Bensch, and B. Hansson. 2010. A strong quantitative trait locus for wing length on chromosome 2 in a wild population of great reed warblers. Proc R Soc Lond B 277:2361-2369.

Yang, J., B. Benyamin, B. P. McEvoy, S. Gordon, A. K. Henders, D. R. Nyholt, P. a. Madden et al. 2010. Common SNPs explain a large proportion of the heritability for human height. Nature Genetics 42:565-569.

Yang, J., T. a. Manolio, L. R. Pasquale, E. Boerwinkle, N. Caporaso, J. M. Cunningham, M. de Andrade et al. 2011. Genome partitioning of genetic variation for complex traits using common SNPs. Nature Genetics 43:519-525. 
Figure legend

Figure 1. Great tits (Parus major) and the traits studied by Robinson et al. (2013) and Santure et al. (2013). Clockwise from upper left: Incubating in a nest box (photo by Sandra Bouwhuis); a clutch of eggs (photo, Simon Evans); a juvenile great tit (photo, Sandra Bouwhuis); measuring wing length (photo, Stephen Menzie). 


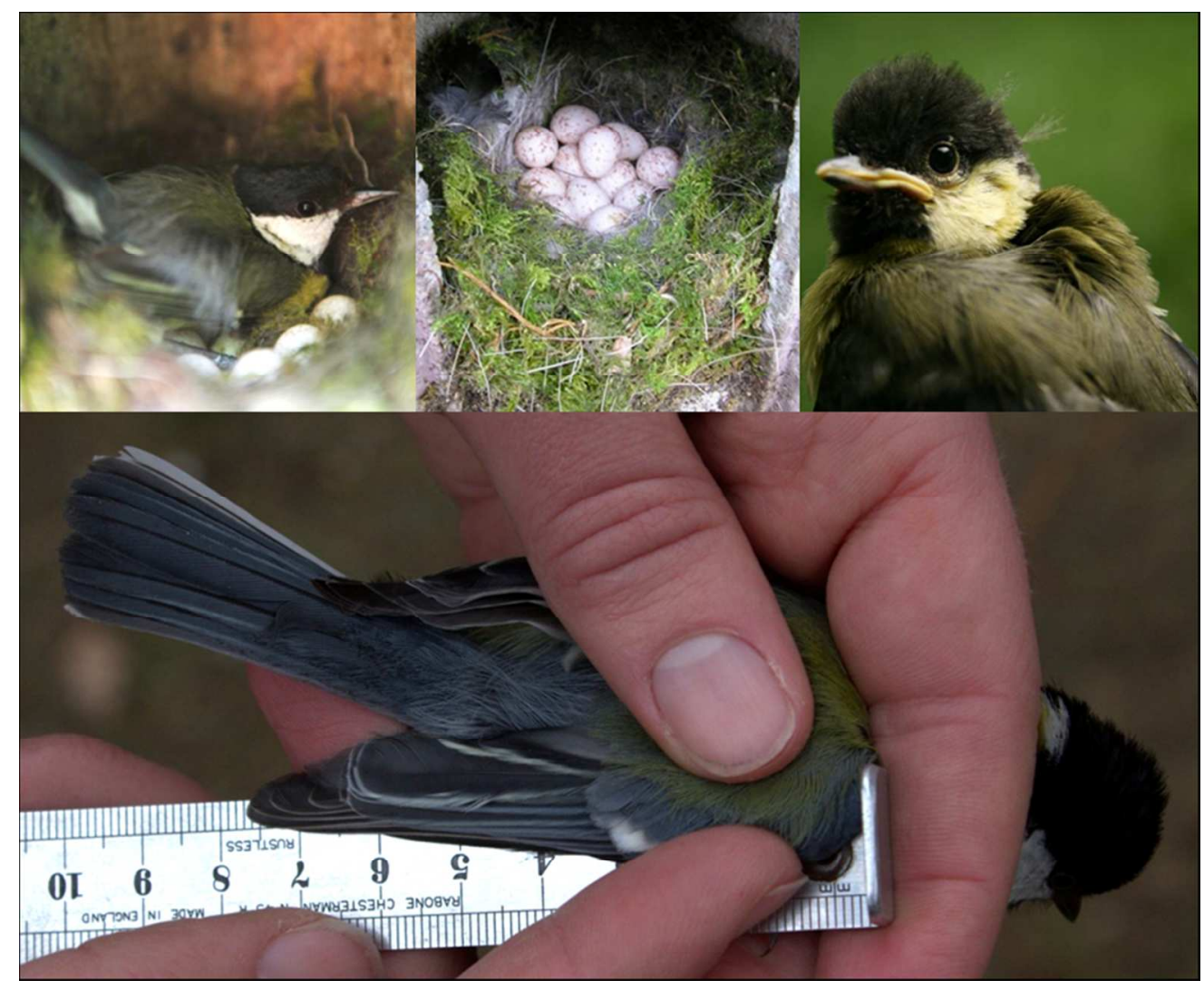

$150 \times 123 \mathrm{~mm}(150 \times 150 \mathrm{DPI})$ 